\title{
Hábitos de higiene oral en la población escolar 丩 a adulta española
}

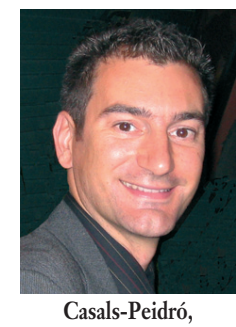

Elías

\section{Oral hugiene habits in spanish school children and adults}

\section{Casals-Peidró, Erías}

Doctor en Odontología Departamento de Odontoestomatología Universidad de Barcelona. Cátedra de Odontología Preventiva y Comunitaria

\section{Correspondencia}

Elías Casals Peidró

Facultad de Odontología. Universidad de Barcelona

Campus Universitario de Ciencias de la Salud

Feixa Llarga $\mathrm{s} / \mathrm{n}$

08907-L'Hospitalet de Llobregat (Barcelona)

E-mail: ecasals@ub.edu

\begin{abstract}
Resumen: Introducción: de acuerdo a la evidencia científica existente, el control de la placa bacteriana (mecánico y químico) acompañado del uso de fluoruros tópicos se establece como la base en el mantenimiento de una dentadura sana. La Federación Dental Internacional (FDI) establece el cepillado dental con una pasta dental fluorada dos veces por día como el patrón básico de higiene dental personal, pudiendo ser mejorado con el uso de elementos adicionales de higiene interproximal (como la seda dental o los cepillos interproximales) o de colutorios (antisépticos o fluorados). Material y método: se recopila información acerca de los hábitos de higiene oral de la población española (escolar y adulta) provenientes de cuestionarios de salud junto a datos de estudios de mercado de venta de productos (cepillos y colutorios) y se relacionan con la epidemiología de caries y enfermedad periodontal. Resultados: Ios hábitos de higiene dental personal en España, pese a una positiva evolución en los últimos años, aún se encuentran lejos del patrón de excelencia deseable y a la cola de los países desarrollados. Conclusión: para conseguir una mejor salud oral de la población española deben mejorarse los hábitos de higiene oral.
\end{abstract}

Palabras clave: Salud oral, Cepillado, Enjuagues, Seda dental, Instrumentos personales de cuidado de salud oral.

\begin{abstract}
Introduction: according to the available scientific evidence, the mechanical and chemical control of the bacterial plaque biofilm supplemented by the use of local fluorides is established as the cornerstone in the maintenance of healthy teeth. The International Dental Federation (FDI) establishes dental brushing with a fluoridated toothpaste twice per day as the basic personal dental tooth cleaning pattern, which could be improved with the use of additional elements of interproximal hygiene (as dental floss or interproximal brushes) or the adjunctive action of mouthwashes (antiseptic or fluoridated). Material amd method: data are compiled regarding oral hygiene habits of the Spanish population (schoolchildren and adults) by means of health questionnaires and through market research of product sales (toothbrushes and mouthrinses) and are related to the epidemiology of caries and periodontal disease. Results: personal tooth cleaning habits in Spain, in spite of a positive evolution in the last years, are still far from the pattern of desirable excellence and among the worst of developed countries patterns. Conclusions: in order to obtain a better oral health of the Spanish population, their habits of oral hygiene must be improved.
\end{abstract}

Key words: Oral health, Toothbrushing, Mouthwashes, Dental floss, Home care dental devices.

BIBLID [1138-123X (2005)10:4; julio-agosto 369-496]

Casals-Peidró E. Hábitos de higiene oral en la población escolar y adulta española. RCOE 2005;10(4):389-401. 


\section{Introducción}

\section{La efectividad del control de placa frente a la enfer- medad de caries y las enfermedades periodon- tales}

La caries es una enfermedad infecciosa que se manifiesta por la desmineralización de los tejidos dentarios (lesión de caries). Esta desmineralización, reversible en sus estadios iniciales, puede provocar la destrucción del tejido dentario. La existencia de bacterias es imprescindible para el desarrollo de esta enfermedad. El estudio de Orland ${ }^{1}$ demostró científicamente esta relación, ya intuida con anterioridad, al comprobar que ratas de laboratorio libres de bacterias mantenidas a partir de una dieta cariogénica, basada en sacarosa, no desarrollaban lesiones de caries mientras que si la misma dieta era utilizada por parte de ratas no libres de bacterias, estas sí que desarrollaban lesiones. Además, las ratas de laboratorio libres de bacterias y lesiones, mantenidas con una dieta rica en sacarosa, acababan desarrollando la enfermedad al adquirir bacterias del medio después de convivir en un mismo espacio físico con las ratas no libres de bacterias.

Aún siendo las bacterias la causa demostrada científicamente de la enfermedad de caries, en estudios de laboratorio con animales, la evidencia disponible sobre estudios que evalúen la efectividad del control de la placa bacteriana sobre la enfermedad de caries en ausencia de fluoruros son escasos y en general, poco consistentes, aceptándose en la actualidad la hipótesis que el control de placa no acompañado de flúor no tiene un

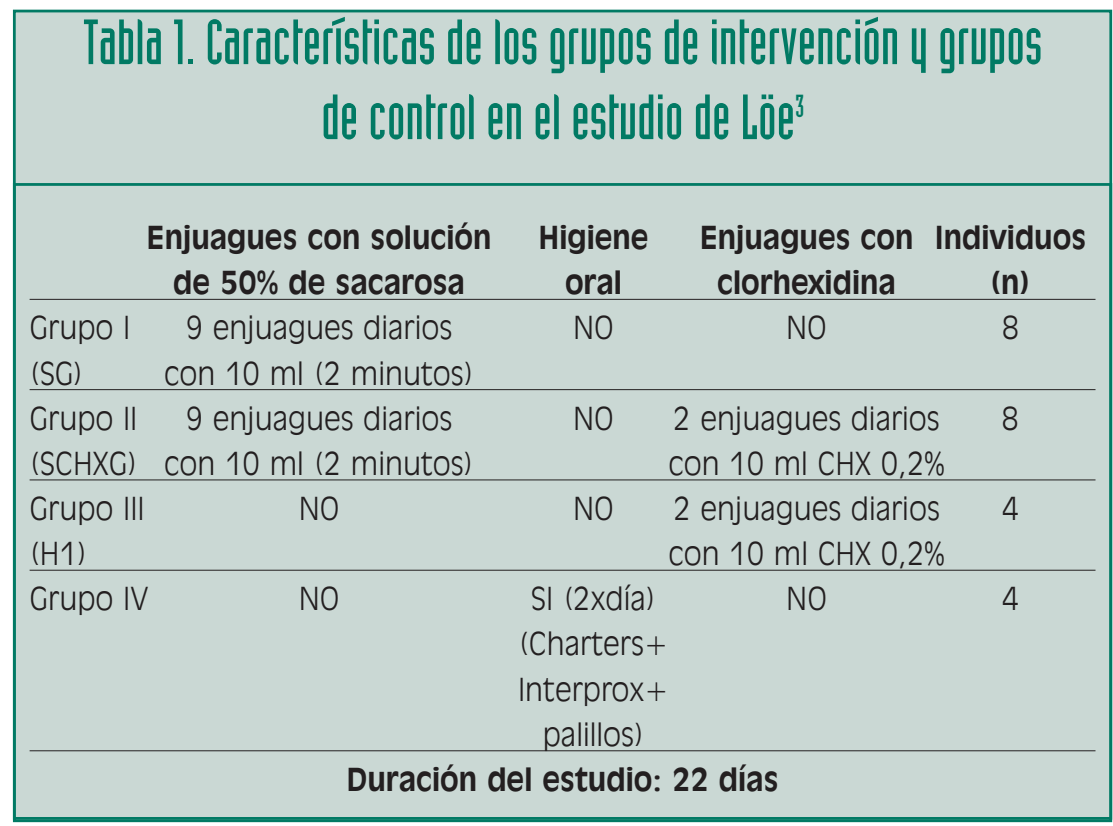

efecto preventivo importante frente a la enfermedad de caries ${ }^{2}$. A modo de ejemplo, de esta inconsistencia de la literatura, podemos analizar uno de los artículos frecuentemente referenciados como base científica del efecto preventivo del control de placa (cepillado) frente a la caries: el estudio de Löe ${ }^{3}$. En este estudio, desarrollado hace más de 30 años, se crearon dos grupos de intervención (cada uno compuesto por ocho individuos) y dos grupos control (formados cada uno por sólo cuatro individuos) (tabla 1). En este estudio se podía comprobar como el índice de caries había aumentado más en el grupo que se enjuagaba con una solución azucarada sin control de placa que en el grupo que además de enjuagar, con una solución azucarada controlaba la placa con enjuagues de clorhexidina. Este aumento más reducido era similar al que experimentaban los grupos control que mantenían un control quími- co (enjuagues con clorhexidina) o mecánico (cepillado más cepillos interproximales) sin realizar enjuagues de solución azucarada (fig.1). Tras los 22 días de estudio, se reinstauraba el control de placa y se realizaba la aplicación tópica de fluoruro retornando todos los participantes a sus niveles de caries iniciales. De la información de este estudio, con un número de participantes muy bajo, parece que podríamos deducir que el control de placa a 22 días reduce parcialmente la tendencia de aparición de nuevas lesiones de caries en ausencia de fluoruros pero que es la aplicación tópica de fluoruro la que demuestra conseguir un verdadero efecto anticariogénico en todos los participantes. En cambio, los autores y quienes citaban su artículo, han valorado los resultados de este estudio como la base científica de que el control de placa per se tiene un efecto anticariogénico que hoy en día la evidencia cientí- 


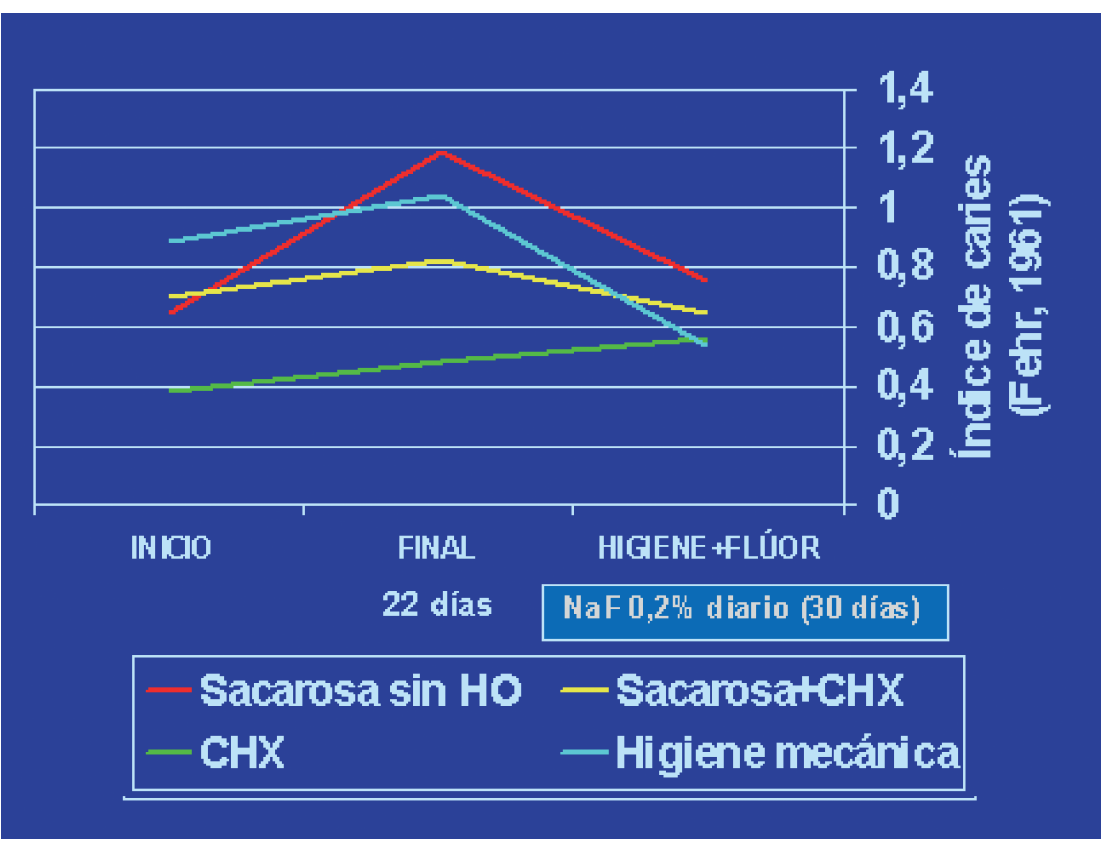

Figura 1. Evolución en los índices de caries de los grupos de intervención y control (Tabla 1) durante la fase experimental (22 dias) y tras la reinstauración de higiene oral y la aplicación de fluoruro tópico.

fica tiende a infravalorar colocando la aplicación de fluoruros como el elemento primordial en la prevención de la caries.

La relación causa-efecto entre la acumulación de placa a nivel gingival y la aparición de inflamación gingival (gingivitis) fue demostrada por otro clásico estudio de Löe en el que los individuos que permitían la acumulación indiscriminada de placa en ausencia de higiene oral desarrollaban una inflamación en sus encías que remitía completamente tras el control de la placa, ya fuera mecánicamente -mediante cepillado- o químicamente -mediante un antiséptico en colutorio, que en este caso fue clorhexidina- ${ }^{4}$.

Por tanto, de acuerdo a la evidencia disponible en la actualidad, el con- trol de placa (mecánico y químico) acompañado del uso de fluoruros tópicos se ha establecido como la base del mantenimiento de una dentadura sana. De hecho, la edad no es una variable importante en el estado periodontal cuando se mantiene una buena higiene oral durante toda la vida $^{5}$. En base a esta evidencia, la Federación Dental Internacional (FDI) estableció el cepillado dental con una pasta dental fluorada dos veces por día como el patrón básico de cuidado dental personal ${ }^{4}$, pudiendo ser mejorado con el uso de elementos adicionales de higiene interproximal (como la seda dental o los cepillos interproximales) o de colutorios (antisépticos o fluorados).

De acuerdo a la evidencia disponible, unas buenas pautas del hábito de higiene oral entre los más pequeños deberían iniciarse con la erupción de los primeros dientes (6-8 meses) los cuales deberían ser limpiados diariamente con una gasa o cepillo humedecido con un enjuague fluorado de concentración diaria para iniciar el aporte de fluoruro tópico inmediatamente tras la erupción. El cepillado de los dientes debería iniciarse diariamente, sin pasta, aproximadamente al año de edad (también empapado con un colutorio fluorado) y siempre realizado por un adulto, introduciendo el uso de pastas dentales fluoradas con formulación infantil $(500$ ppm de flúor), una vez al día, a partir de los 2-3 años, en función del riesgo de caries. con el objetivo de establecer el hábito de cepillado es bueno que el niño intente cepillarse sus dientes por si solo pero sin la utilización de pasta dental, adicionalmente al cepillado diario con pasta fluorada realizada por un adulto, con el objetivo de evitar un posible riesgo de fluorosis dental por la fracción de pasta ingerida. Además, la supervisión de un adulto durante la higiene oral debería mantenerse aproximadamente hasta los seis años. A partir de los seis años el cepillado debería realizarse como mínimo dos veces al día con una pasta dental fluorada, de acuerdo a las recomendaciones de la FDI, pudiendose utilizar pastas dentales con una concentración de flúor a partir de 1000 ppm.

La utilización de enjuagues (fluorados o como ayuda al control de placa) podría iniciarse a partir de los seis años, edad considerada óptima por controlarse perfectamente el control de la deglución así como por ser la época de inicio de la erupción de la dentición permanente. 


\section{Material u método}

Desgraciadamente, el control real de la placa por parte de la población es bastante imperfecto, de acuerdo a las estadísticas disponibles sobre hábitos de cepillado, uso de instrumentos de higiene interproximal y de colutorios. Además, los estudios sobre el tiempo medio dedicado a esta labor sitúan el tiempo invertido incluso por debajo de los sesenta segundos.

conocer los hábitos reales de higiene oral de la población española no es una tarea fácil. Podemos obtener información proyectando un posible escenario a partir de tres grandes grupos de datos: las encuestas de salud sobre hábitos de higiene oral; los datos provenientes de estudios de mercado sobre uso y venta de productos de higiene oral, y la epidemiología de las enfermedades orales.

Hemos divido los resultados obtenidos en la búsqueda de datos relacionados con los hábitos higiénicos de la población española en dos grupos: escolares y adultos. Cabe mencionar que el montante de estudios epidemiológicos realizados en escolares supera, con creces, los realizados en población adulta. Ello es debido al desarrollo de programas preventivos en diversas comunidades autónomas y a la consiguiente necesidad de una posterior evaluación.

\section{Resultados}

\section{Hábitos de cepillado en los escolares españoles a par- tir de los cuestionarios de salud oral}

conocemos de antemano que los cuestionarios sobre hábitos de salud

\begin{tabular}{|c|c|c|c|c|c|c|}
\hline Ámbito & $\begin{array}{c}\text { Año } \\
\text { del trabajo } \\
\text { de campo }\end{array}$ & Edad & Muestra & $\begin{array}{c}\text { Cepillado } \\
\text { diario } \\
\end{array}$ & $\begin{array}{l}\text { Una } \\
\text { vez }\end{array}$ & $\begin{array}{l}\text { Más } \\
\text { de una }\end{array}$ \\
\hline Canarias $^{7}$ & 1990 & 12 años & & $95,15 \%$ & & $44,3 \%$ \\
\hline Canarias $^{8}$ & 1997 & 0-14 años & $n=231$ & $79 \%$ & & \\
\hline Canarias $^{7}$ & 1998 & 12 años & $n=1.063$ & $90,5 \%$ & $39,2 \%$ & $51,3 \%$ \\
\hline Navarra $^{9}$ & 1997 & 12 años & & $79 \%$ & $39,5 \%$ & $39,5 \%$ \\
\hline Navarra $^{9}$ & 1997 & 14 años & & $79,6 \%$ & $46,4 \%$ & $30,9 \%$ \\
\hline Navarra $^{9}$ & 2002 & 12 años & $n=392$ & $85,7 \%$ & $36,3 \%$ & $49,4 \%$ \\
\hline Navarra $^{9}$ & 2002 & 14 años & $n=412$ & $79,6 \%$ & $26,6 \%$ & $53 \%$ \\
\hline Castilla y León ${ }^{19}$ & 1993 & 12 años & $n=953$ & $80,9 \%$ & $41,3 \%$ & $39,6 \%$ \\
\hline Castilla y León ${ }^{19}$ & 1993 & 14 años & $n=913$ & $78,2 \%$ & $38,2 \%$ & $40 \%$ \\
\hline Castilla y León ${ }^{20}$ & 1997 & 14 años & $n=19.803$ & $96,4 \%$ & $34,8 \%$ & $61,6 \%$ \\
\hline Castilla y León ${ }^{21}$ & 1999 & 12 años & & $89 \%$ & $35,6 \%$ & $53,5 \%$ \\
\hline Castilla y León ${ }^{21}$ & 1999 & 14 años & & $93,4 \%$ & $36,3 \%$ & $57,1 \%$ \\
\hline Vitoria-Casteiz $z^{13}$ & 1999 & $13-20$ años & $n=1.292$ & $95,7 \%$ & $53,8 \%$ & $41,9 \%$ \\
\hline Calicia $^{22}$ & 2000 & 12 años & $n=1.117$ & $83,1 \%$ & & \\
\hline España $^{6}$ & 1997 & 7-13 años & $n=123$ & $78 \%$ & $22,7 \%$ & $55,3 \%$ \\
\hline
\end{tabular}

oral tienen un sesgo importante ya que el encuestado tiende a ofrecer una respuesta de cortesía más parecida a lo que es considerado socialmente como aceptable frente a la información real. Además, la metodología y las muestras utilizadas por los diferentes estudios que abordan este tema no son siempre comparables (variando el tamaño de la muestra, las preguntas realizadas o las edades de la población diana), requiriendo los datos obtenidos de una información adicional sobre el estudio para comprender mejor cual es el valor real de estos datos desde un punto de vista cualitativo. Aún así, debemos utilizar los datos con los que contamos y valorar especialmente la evolución de los resultados provenientes de encuestas muy similares y, en particular, de aquellos estudios que se repiten periódicamente, con el objetivo de obtener una buena aproximación sobre la evolución real de los hábitos higiénicos de los españoles.

Los hábitos de los escolares españoles, objeto de diversas campañas escolares de promoción de la salud oral promovidas por la administración y las empresas del sector, han ido mejorando progresivamente en los últimos años, a tenor de los datos ofrecidos por los cuestionarios de salud.

El libro blanco sobre la salud bucodental en España ${ }^{6}$, desarrollado en 1997, nos ofrecía, para un amplio abanico de edades que comprendía desde los 7 hasta los 13 años ( $n=123$ ) un porcentaje de escolares que se cepillaban dos o tres veces al día de un $55,3 \%$. Este dato se obtuvo a partir de encuestas personales domiciliarias realizadas a los padres de los esco- 


\begin{tabular}{|c|c|c|c|c|c|c|c|c|c|c|c|c|}
\hline País & $\begin{array}{c}11-\mathrm{H} \\
93-94\end{array}$ & $\begin{array}{c}11-\mathrm{H} \\
01-02 \\
\end{array}$ & $\begin{array}{c}11-M \\
93-94\end{array}$ & $\begin{array}{l}11-M \\
01-02 \\
\end{array}$ & $\begin{array}{c}13-\mathrm{H} \\
93-94\end{array}$ & $\begin{array}{c}13-\mathrm{H} \\
01-02 \\
\end{array}$ & $\begin{array}{c}13-\mathrm{H} \\
93-94 \\
\end{array}$ & $\begin{array}{c}13-\mathrm{H} \\
01-02 \\
\end{array}$ & $\begin{array}{c}15-\mathrm{H} \\
93-94\end{array}$ & $\begin{array}{c}15-\mathrm{H} \\
01-02 \\
\end{array}$ & $\begin{array}{c}15-\mathrm{H} \\
93-94\end{array}$ & $\begin{array}{c}15-\mathrm{H} \\
01-02 \\
\end{array}$ \\
\hline España & 38 & 50,7 & 51 & 60,8 & 33 & 40,1 & 45 & 56,8 & 28 & 35,8 & 60 & 61,3 \\
\hline Portugal & NP & 44,4 & NP & 62,9 & NP & 51,1 & NP & 64 & NP & 46,4 & NP & 75,1 \\
\hline Italia & NP & 47,3 & NP & 66,8 & NP & 55,8 & NP & 75,2 & NP & 60 & NP & 80,8 \\
\hline Alemania & 70 & 75 & 82 & 82 & 67 & 70,3 & 82 & 83,4 & 60 & 67,3 & 80 & 83,7 \\
\hline Suecia & 79 & 75,1 & 85 & 83,5 & 81 & 77,1 & 91 & 82,2 & 85 & 77,7 & 97 & 86,8 \\
\hline Holanda & $N P$ & 78,7 & $N P$ & 80,9 & $N P$ & 73,7 & $N P$ & 79,4 & NP & 67,8 & $N P$ & 81,1 \\
\hline Dinamarca & 78 & 72,6 & 86 & 81 & 74 & 73,6 & 84 & 82,7 & 73 & 73,6 & 88 & 85,5 \\
\hline Suiza & 76 & 81 & 81 & 86,1 & 74 & 81 & 83 & 90,5 & 71 & 76,5 & 86 & 89,6 \\
\hline Austria & 61 & 69 & 72 & 76,9 & 54 & 65,4 & 66 & 72,7 & 47 & 63,2 & 73 & 79,6 \\
\hline Francia & 52 & 53,4 & 61 & 63,6 & 49 & 56,6 & 68 & 71,9 & 49 & 57,8 & 70 & 77,5 \\
\hline Noruega & 68 & 73,3 & 77 & 80,8 & 70 & 74,9 & 80 & 86,3 & 67 & 73,9 & 88 & 87,2 \\
\hline Escocia & 53 & 59,1 & 65 & 72,5 & 53 & 59,7 & 72 & 77,1 & 55 & 61,2 & 74 & 78,8 \\
\hline Gales & 52 & 58,7 & 65 & 72,3 & 53 & 58,6 & 73 & 78,1 & 58 & 58,5 & 81 & 81,1 \\
\hline Inglaterra & $N P$ & 66,9 & $N P$ & 77,1 & $N P$ & 66,4 & $N P$ & 82 & $N P$ & 67,4 & $N P$ & 85,8 \\
\hline Canadá & 55 & 65,8 & 66 & 74,9 & 58 & 60,7 & 75 & 77,5 & 59 & 62,1 & 79 & 82,2 \\
\hline EEUU & $N P$ & 66,8 & $N P$ & 76,7 & $\mathrm{NP}$ & 61,7 & $N P$ & 79,6 & $N P$ & 63,8 & NP & 80,7 \\
\hline
\end{tabular}

lares. Otro dato interesante, obtenido en este estudio, es el grado de colaboración y supervisión de los padres en las tareas de cepillado de sus hijos menores de seis años: sólo un 42,1\% de padres realiza esta supervisión, que hemos considerado muy importante hasta esta edad.

Algunas encuestas epidemiológicas de salud oral, promovidas por la administración sanitaria, han introducido cuestionarios sobre hábitos de salud que nos ofrecen datos más concretos para una edad determinada y un área geográfica más concreta, como una comunidad autónoma. De este modo, observamos que el $90,5 \%$ de los escolares canarios de 12 años (en un cuestionario realizado a 1063 escolares) declaraba cepillarse los dientes a diario en el año 1998 pero que solo el
51,3\% lo hacía después de cada comida ${ }^{7}$.

En Navarra (en un cuestionario realizado a 412 escolares), el 79,6\% de los escolares navarros autóctonos de 14 años (se excluye a la población inmigrante que sólo representaba un $2 \%$ de la muestra en esta franja de edad) declaraba cepillarse los dientes diariamente en el año 2002 y el $53 \%$ declaraba cepillarse más de una vez al día ${ }^{9}$. Esta última encuesta permite una comparación con los datos del cuestionario distribuido en las anteriores encuestas epidemiológicas $(1987,1997)$ mostrando una mejora apreciable en los hábitos de higiene, ya que declaraban cepillarse diariamente el $70,2 \%$ en 1987 y un $77,3 \%$ en 1997; y cepillarse más de una vez al día el $23,4 \%$ (1987) y el $46,4 \%$ $(1997)^{9}$ (tabla 2).
Esta tendencia positiva de los hábitos de salud de los escolares debe ser situada dentro de un contexto europeo para poder valorar mejor la situación actual. La oficina europea de la Organización Mundial de la Salud (WHO Europe) promueve un estudio, con una periodicidad cuatrienal, sobre los hábitos y los comportamientos relacionados con la salud en escolares de 11, 13 y 15 años, de la mayoría de los países europeos.

Este estudio fue iniciado en 1983/1984 con cuatro países y en su sexta edición (2001/2002) ha abarcado escolares de 35 regiones y países europeos, más Canadá, Israel y EEUU. Este estudio es en la actualidad la mejor comparativa internacional existente en relación a la frecuencia de cepillado, al realizarse la adaptación 
de un cuestionario idéntico para todos los países y regiones participantes (con una muestra estandarizada de aproximadamente 1500 escolares por edad y región estudiada, Io cual representa una muestra global de alrededor de más de ciento cincuenta mil escolares), el cual es monitorizado por técnicos durante su realización en la escuela. Según los datos obtenidos en el estudio HBSC 2001/2002 ${ }^{10^{* *}}$ (Health Behaviour in School-aged children), España obtiene uno de los porcentajes más bajos entre los escolares que declaran cepillarse los dientes más de una vez al día de entre todos los países y regiones participantes en el estudio. Tan sólo un 40,1\% de los escolares y $56,8 \%$ de las escolares de 13 años declararó cepillarse los dientes más de una vez al día en el estudio de 2001-2002. Si comparamos estos datos con los de países con mejores índices de cepillado en escolares podemos comprobar como el $77,1 \%$ de los escolares suecos y el $82,2 \%$ de las escolares suecas de la misma edad declaraban cepillarse más de una vez al día frente a un $73,6 \%$ de los escolares daneses y un $82,7 \%$ de las escolares danesas. Es curioso observar como siempre se cumple, para casi todas las edades y muestras estudiadas, que las chicas tienen una frecuencia de cepillado superior a la de sus compañeros del sexo masculino (tabla 3). Por otro lado, en este estudio se relacionó el hábito de cepillado con variables relativas al nivel económico familiar (bueno/normal/bajo) y a la evolución del estudiante en el medio escolar (bueno/normal/malo), de acuerdo a los datos ofrecidos por el propio escolar, observándose una menor frecuencia de cepillado entre los escolares prove- nientes de familias con un nivel económico bajo y en aquellos escolares con peores resultados académicos ${ }^{11^{*}}$.

Podemos ver la evolución en los datos obtenidos respecto a la anterior participación de España en este estudio, en la edición desarrollada en 1993-94 $4^{12^{*}}$ (tabla 3), donde tan sólo un $33 \%$ de los escolares (frente a un $40,1 \%$ en $2001-02$ ) y un $45 \%$ de las escolares españolas de 13 años (frente al 56,8\% de 2001-02) declaraba cepillarse los dientes más de una vez al día. Si comparamos estos datos con los de países con mejores índices obtenemos que un $81 \%$ de los escolares suecos y un $91 \%$ de las escolares suecas de la misma edad declaraba cepillarse más de una vez al día frente a un $74 \%$ de los escolares daneses y un $84 \%$ de las escolares danesas. Por tanto, vemos como el patrón de cepillado de los escolares españoles ha mejorado. Todos estos datos muestran un incremento paulatino del número de escolares españoles que se cepillan los dientes un mínimo de dos veces al día, de acuerdo a la pauta establecida por la FDI, pero que aún esta por debajo de las cifras alcanzadas por los países escandinavos con cifras de escolares cumpliendo con la pauta básica de higiene oral, que se mantienen en la franja del $80-90 \%$.

\section{Medidas adicionales al cepillado en los escolares españoles a partir de los cuestionarios de salud}

El uso de medidas adicionales al cepillado dental en la población escolar ha sido valorado por un número de estudios muy reducido. Según la encuesta de Canarias (1998) el 6,6\% de los escolares de 12 años declara- ban utilizar el hilo de seda diariamente y un $21,3 \%$ de forma ocasional (frente a un 13,4\% en el año 1990). En Navarra (2002) un 2,2\% de escolares de segundo de secundaria (14 años) declaraban utilizar el hilo de seda diariamente y un $20,8 \%$ de forma ocasional. En Vitoria-Gasteiz, solo un 3,3\% de los adolescentes (13 a 20 años) declaraba utilizar el hilo de seda a diario y un $30,4 \%$ de forma ocasional|13. En Calicia, solo un $12,4 \%$ de los escolares de 12 años declaraba utilizar el hilo de seda.

El estudio internacional $\mathrm{HBSC}^{14}$ nos ofrece una cifra para España un poco mayor a los estudios mencionados para una fecha de realización una década anterior (1985-86) y para la edad de 11 años $(n=1295)$ con un 6\% de los escolares que declaraban utilizar el hilo de seda cotidianamente y un $8 \%$ una vez a la semana. Es destacable que incluso algunos países participantes decidieron introducir una alternativa más en las respuestas como "no sé que es el hilo de seda» con porcentajes de respuesta de hasta un $77 \%$ en Polonia.

En la edición 1993-94 del estudio, el número de escolares españoles ( $n=1507)$ que declaraba utilizar el hilo de seda diariamente llegó a la cifra máxima de un $9 \%$. Cabe destacar que el país con un porcentaje de utilización diaria más alto de entre todos los participantes era Canadá con un 25\% y en Europa, Noruega, con un $17 \%{ }^{11}$. En la última edición de este estudio (2001-02) se eliminó la pregunta en relación al uso del hilo de seda.

En relación al uso de otras medidas adicionales de higiene oral existen muy pocos datos en la bibliografía. Un $4,8 \%$ de los adolescentes vascos 
declaraba una utilización diaria de colutorios ${ }^{13}$ aunque desconocemos el objetivo del mismo (antiplaca o anticariogénico). En cualquier caso, el hábito de realización de enjuagues fluorados entre los escolares españoles es alto, debido a que un gran número de comunidades autónomas han utilizado o continúan utilizando esta actividad como parte de su programa preventivo comunitario de salud oral15.

\section{Hábitos de cepillado en los adultos españoles a partir de los cuestionarios de salud}

Los estudios sobre información relativa a los hábitos de higiene oral de la población adulta española son relativamente más escasos que para la población escolar y suelen venir todos ellos patrocinados por alguna empresa del sector de la higiene dental. El libro blanco sobre la salud bucodental en España ${ }^{6}$, desarrollado en 1997, nos ofrecía, para un amplio abanico de edades a partir de los 14 años $(n=1123)$ un porcentaje de cepillado dos o tres veces al día de un $52,1 \%$ en los hombres y de un $68,8 \%$ en las mujeres (datos obtenidos a partir de encuestas personales domiciliarias).

El hábito de cepillado en la población adulta catalana, mediante encuestas telefónicas en Cataluña $(n=899)$, en edades a partir de los 18 años, obtuvo que un $64,7 \%$ de los encuestados $(48,4 \%$ de hombres y un $73,3 \%$ de mujeres) afirmaban cepillarse los dientes después de cada comida y un $29,3 \%$ adicional $(40,7 \%$ de nombres y un $23,3 \%$ de mujeres) declaraba cepillarse una sola vez al día. Estos datos variaban en función de edad (máximo porcentaje para el grupo $18-25$ años con un $72,2 \%$ de individuos que declaraban cepillarse después de cada comida), nivel de estudios (máximo para el grupo con estudios universitarios, con un $78,9 \%$ de individuos que declaraban cepillarse después de cada comida) así como con el nivel de renta (con un porcentaje de cepillado después de cada comida del $70,8 \%$ para la franja de renta superior frente a un 55,7\% para la franja inferior $)^{16}$.

La encuesta de salud de Canarias ${ }^{8}$, desarrollada en 1998, en edades a partir de los 14 años ( $n=2228$ ) me-diante encuesta a domicilio, obtuvo que el $88,6 \%$ de los encuestados (un $48,4 \%$ de hombres y un $73,3 \%$ de mu-jeres) afirmaban cepillarse los dientes diariamente. Estos datos variaban en función de edad y sexo (máximo porcentaje para el grupo de mujeres de 15-44 años con un $95,5 \%$ de encuestadas que declaraban cepillarse diariamente y mínimo para el grupo de hombres de más de 65 años con un 71,53\%).

A estos datos generales sobre cepillado no podemos añadir, como datos aplicables a la globalidad de la población, aquellos datos existentes en prensa escrita provenientes de estudios sesgados con poca base científica al estar basados en los datos obtenidos a partir de un segmento de la población que acude al dentista a través de algún programa gratuito de promoción de la salud y, por tanto, a que la muestra estudiada no es representativa del conjunto de la población sino posiblemente tan sólo de aquellas personas con pocos recursos económicos así como una baja frecuentación de visita al dentista. Otras veces, la muestra si puede considerarse representati- va de algún segmento con alguna característica concreta que no desvirtúa el valor del estudio. Cabe mencionar la encuesta sobre hábitos de higiene bucal realizada en el año 20017, entre mayores de 18 años $(n=1000)$, con la característica de que comían habitualmente fuera de sus domicilios (encuesta realizada por vía telefónica y fuera del horario laboral). Esta encuesta reflejaba que solo se cepillaban los dientes fuera de casa un $39,7 \%$ de los hombres y un $60,3 \%$ de las mujeres. El patrón mejoraba ligeramente a mayor nivel de estudios. Es curioso comprobar como la máxima frecuencia de cepillado se produce después de la cena $(88,4 \%)$, seguida del desayuno $(69,2 \%)$ y de la comida $(51,6 \%)$.

\section{Medidas adicionales al cepillado en los adultos españoles a partir de cuestionarios de salud}

El uso de medidas adicionales al cepillado dental en la población adulta mediante una muestra metodológicamente válida ha sido estudiado por un número de estudios muy reducido. Un estudio, realizado en 1996, mediante encuestas telefónicas en Cataluña ( $n=899$ ) obtuvo un $16,13 \%$ de hombres y un $27,84 \%$ de mujeres que afirmaban utilizar habitualmente el hilo de seda, mientras que un $43,4 \%$ de los hombres y un $58,57 \%$ de las mujeres afirmaban utilizar habitualmente un antiséptico bucal ${ }^{9}$.

El libro blanco sobre la salud bucodental en España ${ }^{3}$, desarrollado en 1997 a partir de encuestas personales domiciliarias, nos ofrecía, para un amplio abanico de edades a partir de los 14 años ( $n=1123)$, un porcentaje de utilización del hilo de seda bastante 
inferior al estudio anterior. Mientras un porcentaje del $5,1 \%$ declaraba utilizar el hilo de seda "siempre», un $16,3 \%$ declaraba utilizarlo "algunas veces». Los porcentajes obtenidos en relación al cepillo interproximal ofrecieron porcentajes del 3\% para la opción "siempre» y del 3,1\% para la opción «algunas veces». En relación al uso de enjuagues bucales, los datos son similares a los obtenidos en Cataluña, aunque ligeramente al alza, ya que un $15,7 \%$ de la población declaraba utilizarlos siempre y un $42,7 \%$ ocasionalmente, lo cual nos ofrece una cifra de usuarios de un colutorio de un $58,4 \%$.

En la encuesta realizada a adultos que comían fuera de casa, tan sólo un $4 \%$ utilizaba un colutorio y un $2,8 \%$ la seda dental cuando comían fuera de casa. Cabe mencionar que sólo un $38,2 \%$ declaraba utilizar pasta o gel denta ${ }^{17}$ en su cepillado fuera de casa.

\section{Los datos relacionados con el consumo de pro- ductos para la higiene oral}

En relación al consumo de productos, los datos publicados en fuentes consultables son pocos, de fuentes diversas $y$, muchas veces, carecen de un seguimiento cronológico que permita valorar su evolución. Esto no significa que no existan datos de alto interés provenientes de estudios realizados con fines comerciales por parte de las empresas del sector, pero estos datos son sólo utilizados internamente en el seno de las corporaciones y no son normalmente publicados en ningún medio de acceso público.

Los estudios de mercado son una herramienta estratégica que proporciona información de gran calidad

\begin{tabular}{|c|c|c|c|}
\hline \multicolumn{4}{|c|}{$\begin{array}{l}\text { Tabla } 4 . \text { Venta de cepillos dentales manuales. } \\
\text { Datos en miles de unidades de cepillos vendidos }\end{array}$} \\
\hline & $\begin{array}{c}\text { Cepillos } \\
\text { manuales } \\
\text { farmacia }\end{array}$ & $\begin{array}{c}\text { Cepillos } \\
\text { manuales } \\
\text { food\&drug }\end{array}$ & $\begin{array}{c}\text { Cepillos } \\
\text { manuales } \\
\text { totales }\end{array}$ \\
\hline Marzo-abril 2002 & 907 & 4.021 & 4.928 \\
\hline Mayo-junio 2002 & 1.072 & 3.771 & 4.843 \\
\hline Julio-agosto 2002 & 1.068 & 4.534 & 5.602 \\
\hline Septiembre-octubre 2002 & 915 & 4.523 & 5.438 \\
\hline Noviembre-diciembre 2002 & 944 & 4.050 & 4.994 \\
\hline Enero-febrero 2003 & 1.014 & 4.298 & 5.312 \\
\hline Marzo-abril 2003 & 962 & 4.276 & 5.238 \\
\hline Mayo-junio 2003 & 1.035 & 3.969 & 5.004 \\
\hline Julio-agosto 2003 & 1.074 & 4.612 & 5.686 \\
\hline Septiembre-octubre 2003 & 980 & 4.388 & 5.368 \\
\hline Noviembre-diciembre 2003 & 899 & 3.994 & 4.893 \\
\hline Enero-febrero 2004 & 1.112 & 4.512 & 5.624 \\
\hline Marzo-abril 2004 & 1.085 & 4.817 & 5.902 \\
\hline TOTAL mayo 2002-abril 2003 & 5.975 & 25.452 & 31.427 \\
\hline TOTAL mayo 2003-abril 2004 & 6.185 & 26.292 & 32.477 \\
\hline
\end{tabular}

sobre la situación de la venta y el uso de productos, siendo de vital importancia para el seguimiento de las tendencias en los mercados, la posición en precio de las marcas, el conocimiento de sus cuotas de mercado, la distribución alcanzada y cualquier otro tipo de información asociada a la evolución de los diferentes productos, segmentos y marcas.

Disponemos de datos sobre la evolución de ventas de cepillos dentales manuales en España a partir del panel de detallistas de ACNielsen (empresa dedicada a nivel internacional a la realización de este tipo de estudios de mercado). El panel de detallistas es una muestra representativa de los dos canales de detallistas diferenciados en la venta de productos dentales. El primer canal representa a las oficinas de farmacia y el segundo agrupa, bajo el título de "food and drug", aquellos comercios relacionados con la venta de productos de alimentación, clasificados en función de su tamaño y número de cajas registradoras: hipermercados, supermercados, tiendas tradicionales y droguerías. El segundo panel, el de consumidores, agrupa una muestra representativa del territorio español con más de 6000 hogares españoles.

Con los datos proporcionados por el panel de detallistas, observamos como la venta de cepillos manuales (tabla 4), pese a tener algunas variaciones estacionales, se mantiene bastante estable en los últimos dos años estudiados. De esta manera, en el periodo mayo 2002-abril 2003 se vendieron cerca de 31,5 millones de 


\begin{tabular}{|c|c|c|c|}
\hline & $\begin{array}{c}\text { Más de } \\
\text { una vez } \\
\text { al día (A) }\end{array}$ & $\begin{array}{c}\text { Una } \\
\text { vez } \\
\text { al día (B) } \\
\end{array}$ & $\begin{array}{c}\text { Diaria total } \\
\text { Suma } \\
\text { A+B } \\
\end{array}$ \\
\hline Junio $1992 \quad(n=795)$ & $13,4 \%$ & $32,9 \%$ & $46,3 \%$ \\
\hline Junio $1993(n=1.041)$ & $14,5 \%$ & $33,3 \%$ & $47,8 \%$ \\
\hline Junio $1994 \quad(n=989)$ & $19,9 \%$ & $29,7 \%$ & $49,6 \%$ \\
\hline Junio $1995 \quad(n=1.100)$ & $12,2 \%$ & $34 \%$ & $46,2 \%$ \\
\hline Junio $1996 \quad(n=1.089)$ & $16 \%$ & $30,4 \%$ & $46,4 \%$ \\
\hline Junio $1997 \quad(n=1.079)$ & $16,6 \%$ & $34,9 \%$ & $51,5 \%$ \\
\hline Mayo $1998 \quad(n=1.055)$ & $16,8 \%$ & $32,3 \%$ & $49,1 \%$ \\
\hline Mayo $1999(n=1.040)$ & $17,3 \%$ & $37,5 \%$ & $54,8 \%$ \\
\hline Mayo $2000 \quad(n=1.045)$ & $20,7 \%$ & $30,6 \%$ & $51,3 \%$ \\
\hline Mayo $2001 \quad(n=1.046)$ & $21,5 \%$ & $31,4 \%$ & $52,9 \%$ \\
\hline Mayo $2002 \quad(n=944)$ & $25,6 \%$ & $30,8 \%$ & $56,4 \%$ \\
\hline Junio $2003 \quad(n=959)$ & $23,4 \%$ & $39,6 \%$ & $63 \%$ \\
\hline
\end{tabular}

cepillos manuales mientras que en el periodo mayo 2003-abril 2005 esta cifra se incremento en cerca de un millón de unidades, lo cual supone un aumento aproximado del 3\%. En cualquier caso, de acuerdo a estas cifras, los españoles renovarían su cepillo dental menos de una vez al año, situándose la media en un cepillo cada 16 meses (los datos deberían ser corregidos en función de los ciudadanos desdentados totales que no deben utilizar cepillo dental aunque esta cifra es de difícil cálculo para el global de la población ya que mientras el grupo etario 35-44 años solo presenta un $0,6 \%$ de desdentados totales, esta cifra alcanza un $23,4 \%$ en la franja etaria 65-74 años).

En relación al uso de enjuagues, los datos disponibles provienen de un estudio, tipo ómnibus, desarrollado por la empresa Dympanel, realizado a un panel cerrado de consumidores. El ómnibus es una muestra representativa de la población de la península e Islas Baleares que es compartida por varios clientes, participando cada uno con sus propias preguntas dentro de un cuestionario que permite la repetición de la misma pregunta en el tiempo, permitiendo valorar la modificación de hábitos de compra y de uso de productos. En este caso concreto, el estudio se dirigía a individuos de 16 a 65 años (con un número cercano a 1000 a lo largo de los años) y mostraba la evolución anual en los patrones de consumo de enjuagues, entre junio de 1992 y junio de 2003, obtenidos mediante una entrevista personal domiciliaria.

Los datos muestran como más de la mitad de la población española declaraba utilizar un enjuague de forma diaria y como su uso ha aumentado ligeramente en la última década (tabla 5). Además, la población que utiliza un enjuague más de una vez al día ha ido aumentando, situándose en una cifra alrededor del $40 \%$.

Dentro de este estudio encontramos valoradas algunas variables que inciden en el uso de enjuagues. El tipo de municipio parece tener una influencia ligera. Los habitantes de áreas urbanas $(49,5 \%)$ y de poblaciones entre $\quad 30.001-200.000$ habitantes $(51,9 \%)$ utilizan en una mayor proporción enjuagues si se compara con los habitantes de poblaciones con menos de 5.000 habitantes $(44,9 \%$ ) y de entre 5.001-30.000 habitantes (43,6\%). También existen ligeras variaciones en el uso de enjuagues en relación al nivel socioeconómico, con una utilización del $52,6 \%$ en la franja alta/medioalta comparada a un $44,4 \%$ en la franja baja. Al igual que ocurre en relación al hábito de cepillado, las mujeres declaran utilizar más un enjuague, con un porcentaje del $53,7 \%$ frente al $42,2 \%$ de los hombres. Por edades, la franja $31-45$ años con un $50,8 \%$ de usuarios lidera la utilización de estos productos seguido por un $48,7 \%$ de la franja $46-65$ y un $44,7 \%$ del grupo de edad 16-30 años.

\section{La cultura relacionada con los hábitos de higiene bucodental}

Los conocimientos de la población española en relación al cuidado de su salud oral merecen también un estudio detenido. El estudio Odonto-Estomatologia $2005^{6}$ (en base a 1123 encuestas domiciliarias) obtuvo unas cifras interesantes en relación a la frecuencia de compra de cepillos dentales. Tan sólo el 29,6\% de la población renueva su cepillo dental cada tres meses, mientras que un $17,2 \%$ lo 
renueva cada seis y un $8,1 \%$ cada 12 meses. Este mismo estudio ${ }^{6}$ establece que un $40,1 \%$ renueva su cepillo "cuando se gasta» (término subjetivo que no nos permite conocer si se encontrará en una franja aceptable o no).

Según el estudio realizado entre los adolescentes de Vitoria-Casteiz ${ }^{13}$, de edades comprendidas entre los 13 y 20 años (media $=15,4 \pm 1,59 ; n=1292$ ), sólo el $20,7 \%$ declaraba cambiar su cepillo trimestralmente mientras un $36,6 \%$ declaraba hacerlo cada seis meses. Llama la atención que un $32,2 \%$ declare recambiar el cepillo anualmente y un $10,4 \%$ cada dos 0 más años. En cualquier caso, estas cifras no se alejan mucho de las obtenidas a partir de los estudios de mercado sobre la venta de cepillos.

En general, la población sí valora la necesidad de la higiene oral ya que la establece como base de las actividades preventivas, situando como principal causa de la caries dental a la falta de higiene en un $58,9 \%$ de los casos, seguido de las comidas dulces en un $23,7 \%$. Además, un $91 \%$ cree que cepillarse los dientes es importante. Por otro lado, el conocimiento acerca de algunas patologías bucales, su prevención y tratamiento debe aún mejorar, ya que ante unas encías que sangran un $70,6 \%$ de los encuestados comprende que debe acudir al dentista pero un $23,2 \%$ cree que debe cepillarse de forma más suave, un $2,3 \%$ de forma más fuerte, un 12,8\% piensa que es inevitable el sangrado en algunas personas y un 7,6\% lo considera normal ${ }^{6}$. Este poco conocimiento acerca de la enfermedad periodontal provoca también una infravaloración de sus consecuencias ya que de

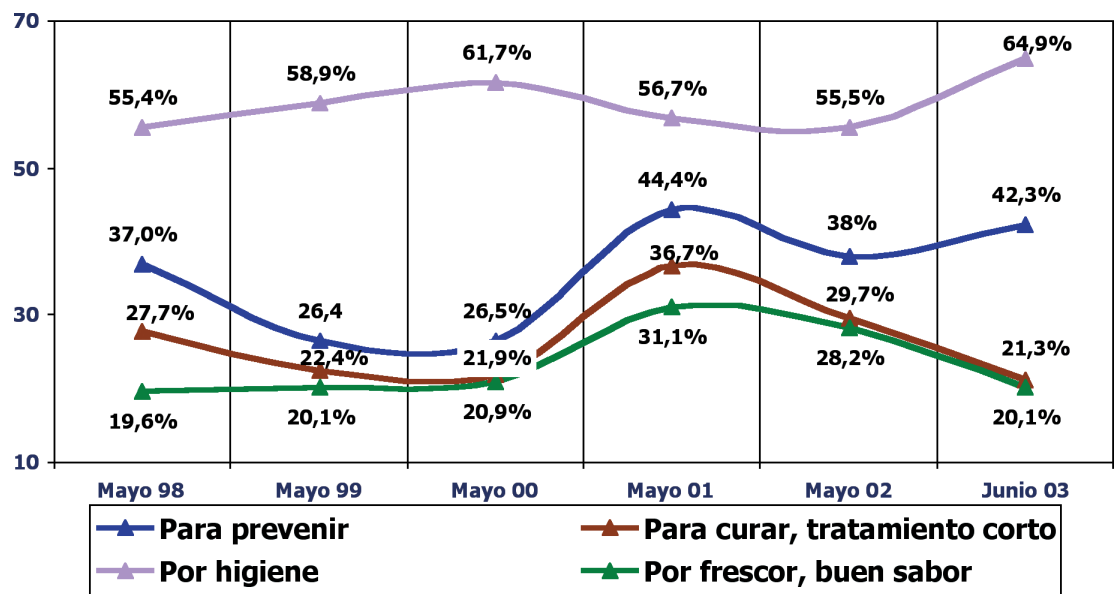

Figura 2. Evolución de los motivos de utilización de colutorios en España (19982003)

acuerdo a la encuesta de salud oral ${ }^{17}$ a adultos, desarrollada en el 2001, sólo el $11,7 \%$ de las personas con sangrado en sus encías estaban preocupadas por este problema. El dentista parece no insistir suficientemente en la motivación sobre los hábitos de higiene oral ya que mientras un $39,7 \%$ de los pacientes ${ }^{17}$ relata haber recibido consejo sobre cepillado y un $14,3 \%$ consejo sobre pastas dentales, un $46,5 \%$ declara no haber recibido ningún consejo sobre higiene bucal en su última visita al dentista. Cabe mencionar que, además, sólo un $11,8 \%$ de los pacientes recibió algún material impreso durante su última visita al dentista.

Las motivaciones para el cuidado de la boca pueden variar entre la población pero es curioso observar como el valor de la estética asume un papel importante, aunque por detrás de la salud. Entre los adolescentes vas$\cos ^{13}$, un $27,9 \%$ atribuyó a la estética dental la razón principal cuidar de sus dientes (frente a un $35,8 \%$ que busca tener una boca limpia) y entre los escolares navarros, un $30,2 \%$ declararon «tener una boca bonita» como una motivación para cepillarse sus dientes (frente a una motivación de "evitar enfermedades» del $68,5 \%)^{9}$. En la última oleada del estudio de mercado sobre el uso de enjuagues en España de Dympanel, el primer motivo para el uso de un colutorio era "por higiene" $(64,9 \%)$, término que englobaba «eliminar alimentos y tener dientes y boca limpios». En segundo lugar se situaba la opción «para prevenir posibles problemas bucales» (42,3\%) quedando en tercer lugar la opción «para curar» $(21,3 \%)$ y en cuarto lugar «por frescor, buen sabor» $(20,1 \%)$ (fig.2).

\section{La epidemiología de caries y enfermedad periodontal en España}

La caries continúa situándose en España entre las enfermedades más prevalentes. Pese a esta alta prevalencia, el índice CAOD a los 12 años se sitúa en niveles muy bajos, según la clasificación de la OMS, habiéndose conseguido disminuir la gravedad de 


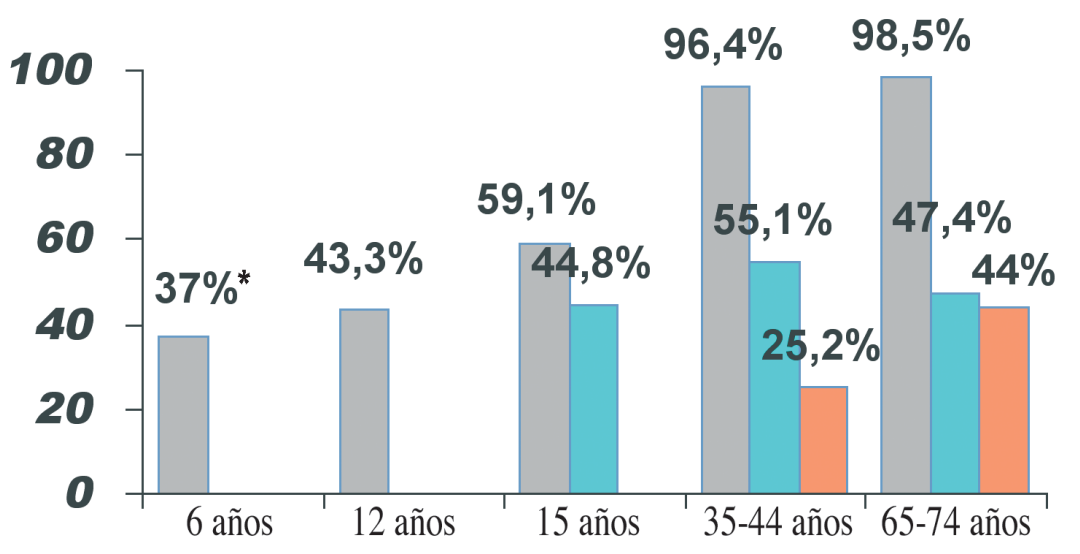

\section{Caries Gingivitis calculo $\square$ Periodontitis}

Figura 3. Prevalencia de caries y enfermedad periodontal por cohortes de edad en España (Encuesta de salud bucodental 2000).

*Prevalencia dentición decidual más definitiva.

la patología en las edades infantiles, situando a España, dentro del grupo minoritario de países con índice CAOD muy bajo. Los índices de caries de nuestra población adulta no se corresponden con los que cabría esperar en función de las proyecciones de los índices infantiles, siendo superiores a las previsiones y evidenciando, muy probablemente, lo que se entiende como efecto cohorte. Aún así, la prevalencia aumenta con la edad, siendo de un $33 \%$ a la edad de 5-6 años (para dentición decidual) y aumentando hasta un $98,5 \%$ en la franja de edad de 65-74 años, de acuerdo con la última encuesta epidemiológica española del año 2000 (fig.3). Pese a esta elevada prevalencia, el número de lesiones por persona ha ido disminuyendo progresivamente, tal y como hemos citado, en los últimos años, pasando de un CAOD, a la edad de 12 años de 4,1 en 1984, a un 2,3 en 1993, y hasta llegar un CAOD de 1,1 en el último estudio del año 2000. Incluso la prevalencia también ha disminuido lige- ramente en las edades infantiles, referida a la dentición permanente a los 12 años, pasando del 68\% (1993) al $43 \%(2000)$

En la franja de edad 35-44 años no ha habido modificación en la prevalencia, aunque si existe una ligera disminución del índice CAOD de 10,9 (1993) a un 8,4 (2000). En la franja de 65-74 años también ha disminuido, al pasar de 21,1 (1993) al 18,1 (2000).

En relación con la enfermedad periodontal se ha producido una reducción de gingivitis y de presencia de cálculo en las edades jóvenes. Mientras en 1993 tan sólo el 25\% de los adolescentes de 15 años estaban periodontalmente sanos, actualmente el $55,3 \%$ no presenta ni sangrado ni cálculo. En cambio en la franja de edad de 35-44 años tan sólo un $19,3 \%$ de los individuos está periodontalmente sano y este porcentaje disminuye hasta el $8,7 \%$ en el grupo de edad de los 65-74 años. En relación a la franja de edad 35-44 años, la prevalencia de periodontitis -bolsas pe-riodontales moderadas 0 severas diagnosticadas como IPC 2 y 3 - ha disminuido notablemente de un $49,2 \%$ (1993) al 25,6\% (2000). En la franja de edad de 65 a 74 años el porcentaje de sujetos con bolsas periodontales moderadas o severas, diagnosticadas como IPC 2 y 3 , también ha disminuido en los últimos años, pasando de un porcentaje de un 56,3 a un $44 \%{ }^{18}$.

En relación a los porcentajes de población con presencia de cálculo observamos como mientras en el colectivo más joven (15 años) esta cifra es relativamente baja $(28,2 \%)$, se alcanzan cifras mucho más elevadas entre la población adulta de la franja de edad 35-44 años $(69,8 \%$ ) y aún superiores para la franja de edad 65-74 años con un $86,9 \%{ }^{18}$.

Por lo tanto, estas enfermedades afectan a un porcentaje considerable de la población pero con diferencias significativas según los grupos de edad siendo todos ellos susceptibles de una mejora en sus hábitos de higiene oral. La reducción de la presencia de gingivitis, en los jóvenes, posiblemente obedece a una mejora de los niveles de higiene. La mejora de los índices de prevalencia, de la enfermedad periodontal en la cohorte de adultos jóvenes, coincide con los datos de una mayor utilización de los servicios dentales en este grupo, si bien no existen datos acerca de la evolución en los patrones de hábitos higiénicos ni estudios longitudinales comparables. La alta incidencia de enfermedad periodontal entre los adultos indica que en la mayoría de casos la higiene oral podría y debería ser mejorada considerablemente. 


\section{Conclusiones}

Solo cuando se ha alcanzado una frecuencia del habito de higiene oral correcta podemos mejorar la realización técnica del mismo con el objetivo de mejorar la higiene oral; por tanto, la base de una buena prevención de la caries y la enfermedad periodontal deben basarse en una frecuencia mínima de cepillado.

\section{Conclusiones relacionadas con los escolares españoles}

- Los datos epidemiológicos del estado de salud oral de la población muestran como los niveles de caries se han reducido paulatinamente en los últimos años. Aún así un $43,3 \%$ de los escolares españoles de 12 años presentan lesiones de caries y el $44,8 \%$ presentan gingivitis o cálculo en su dentición.

- Existe una positiva evolución en los hábitos de cepillado ya que los últimos estudios muestran unos porcentajes de cepillado entre los escolares adolescentes, de acuerdo a las recomendaciones internacionales de la FDI de un mínimo de dos veces al día, situados entre el 50 y el $55 \%$, siendo siempre mejores en el sexo femenino, pero lejos de los porcentajes alcanzados por algunos países escandinavos con cifras alrededor del $80 \%$ (no hemos de olvidar que cualquier dato proveniente de una encuesta tiende a ofrecer unos datos que sobrestiman la realidad).

- Los porcentajes de cepillado "como mínimo de una vez al día» se sitúan alrededor del 90\%, lo cual signi- fica que más que iniciar el hábito del cepillado, lo importante a esta edad es conseguir una pauta más frecuente, a la cual debería añadirse una técnica correcta.

- En relación con los hábitos de higiene interproximal, podemos comprobar como la frecuencia de realización de estos hábitos son muy bajos en edades infantiles 0 juveniles, con un porcentaje de usuarios ocasionales del hilo de seda entorno al 20\% mientras los usuarios habituales se sitúan entorno al $5 \%$

\section{Conclusiones relacionadas con los adultos españoles}

- En la población adulta, el porcentaje de personas que declaran cepillar sus dientes un mínimo de dos veces al día varía tremendamente en función del sexo. De esta manera, cerca de tres cuartas partes de las españolas declaran cepillarse un mínimo de dos veces al día, porcentaje sólo alcanzado por aproximadamente la mitad de los españoles de sexo masculino. Cabe destacar que el horario preferido para cepillarse los dientes es después de la cena, seguido por después del desayuno.

- El hilo de seda es utilizado de forma habitual por una cuarta parte de la población mientras que los colutorios alcanzan cifras superiores a la mitad de la población, siendo más frecuente el binomio cepillado-enjuague que el cepillado-hilo de seda. Estos datos se relacionan perfectamente con los estudios de venta de colutorios que muestran un número de usuarios constante a lo largo de la última déca- da con un aumento progresivo de aquellos que lo utilizan un mínimo de dos veces al día.

- Los conocimientos educativos de la población en relación con las patologías bucales más prevalentes (caries y enfermedad periodontal) continúan siendo bajos, existiendo aún conceptos erróneos por parte de la población como el evitar el cepillado en caso de sangrado de las encías o el desconocimiento sobre los efectos a largo plazo de estas patologías. Además, los profesionales pueden y deben mejorar la información de sus pacientes ya que cerca de la mitad de los mismos declaran no haber recibido ningún consejo sobre higiene bucal en su última visita al dentista y sólo un $11,8 \%$ recibió algún documento informativo escrito.

- Pese a los hábitos declarados, sólo una cuarta parte de la población declara cambiar su cepillo cada tres meses y este dato se ve reflejado en la venta anual de cepillos, que pese a mejorar, lenta pero progresivamente, no alcanza la venta de un cepillo/año por habitante. Los esfuerzos para la prevención y el tratamiento de estas enfermedades deben continuar dirigiéndose a la concienciación de la población sobre la necesidad de una buena higiene oral (cepillo + hilo de seda + enjuague) y al diagnóstico. Parece necesario buscar nuevas fórmulas de motivación del paciente, en todos los métodos de eliminación de placa, especialmente en aquellos más fáciles de cumplir y más habituales por parte de la población, como el cepillado o los colutorios. 


\section{Bibliografia recomendada}

Para profundizar en la lectura de este tema, el/los autor/es considera/an interesantes los artículos que aparecen señalados del siguiente modo: *de interés * ${ }^{*}$ de especial interés.

1. Orland FJ, Blayney JR, Harrison RW, Reyniers JA, Trexler PC, Ervin RF, Gordon HA, Wagner $M$. Experimental caries in germ-free rats inoculated with enterococcus. J Amer Dent Assoc 1955;50:259-72.

2. The Swedish Council on Technology Assesment in Health Care. Prevention of dental caries. A systematic review. Summary and conclusions. Stockholm: SBU, October 2002 (accedido el 2 de julio de 2004 en www.sbu.se/filer/content0/publikationer/1/dentalcare_2002/dentalcarieslut.pdf)

3. Löe H, von der Fehr FR, Schiött CR. Inhibition of experimental caries by plaque prevention. Scan J Dent Research 1972;80:1-9

4. Löe H. Oral hygiene in the prevention of caries and periodontal disease. Int Dent $\mathrm{J}$ 2000;50 (3): $129-39$

5. Sheiham A, Netuveli G. Periodontal diseases in Europe. Periodontology 2000, 2002;29:104-21.

6. Libro blanco. Odonto-Estomatología 2005. Barcelona: Lácer, 1997.

7. Gómez-Santos G. II Estudio Epidemiológico de la Salud Bucodental Infantil en Canarias, 1998. Servicio Canario de Salud, Serie Epidemiología, 2000.

8. Servicio del Plan de Salud e Investigación del Servicio Canario de Salud. Encuesta de Salud de Canarias 1997. Consejería de Sanidad y Consumo del Gobierno de Canarias. Santa Cruz de Tenerife, 1998. (accedido el 30 de julio de 2004 en http://www.gobcan.es/sanidad/scs/1/plansalud/esc/ppal_esc.htm)

9. Doria-Bajo A, Cortés-Martinicorena FJ, AsenjoMadoz MA, Sainz de Murieta-Iriarte I, RamónTorrell JM, Cuenca-Sala E. Hábitos de higiene oral en los escolares de Navarra. Arch Odontoestomatol Prev Comunitaria 2003;19:515-22

10.** Currie C, Roberts C, Morgan A et al. Young people's health in context. Health Behaviour in School-Aged Children (HBSC) study: international report from the 2001/2002 survey. World Health Organization. 2004 (accedido 22 de julio de 2004 en http://www. euro.who.int/Document/e82923.pd)

Este estudio (HBSC) es en la actualidad la mejor comparativa existente en relación a la frecuencia de cepillado, al realizarse la adaptación de un cuestionario idéntico para todos los países y regiones participantes monitorizado por técnicos durante su realización en las escuelas.

11.* Kuusela S, Honkala E, Kannas L, Tynjala J, Wold B. Oral hygiene habits of 11-year-old schoolchildren in 22 European countries and Canada in 1993/1994. J Dent Res 1997 76:1602-9.

Artículo que comenta la información de la edición 1993/94 del estudio HBSC en relación a los hábitos de higiene oral en los escolares de países desarrollados.

12.* King A, Wold B, Tudor-Smith C, Harel Y. The Health of Youth: A cross-national survey. WHO Regional Publications, European Series No. 69. 1996. (accedido el 22 de julio de 2004 en http://www.hbsc.org/downloads/HealthofYouth1.pdf) Edición 1993/94 del estudio HBSC en el cual aparece la relación de los hábitos de higiene oral en los escolares de países desarrollados que participan en este estudio.

13. Lafuente PJ, Gómez Pérez de Mendiola FJ, Aguirre B et al. Estilos de vida determinantes de la salud oral en adolescentes de VitoriaGasteiz: evaluación. Aten Primaria 2002;29: 213-7.

14. Honkala E, Kannas L, Rise J. Oral health habits of schoolchildren in 11 European countries. Int Dent J 1990;40:211-7.

15. Esparza F, Cortés Martinicorena J. Servicios públicos de salud bucodental en España.
Legislación y cartera de servicios en las CCAA. Marzo 2001. Córdoba, Sociedad Española de Epidemiología y Salud Pública Oral, 2001. (accedido el 15 de junio de 2004 en http://www.infomed.es/sespo/monografia.html)

16. Colegio Oficial de Odontólogos y Estomatólogos de Cataluña. Presente y futuro del sector odontoestomatológico en Cataluña: años 1996-2005. Barcelona: COEC, Sorpama, 1997.

17. Encuesta sobre higiene bucal 2001. Madrid, Fundación Dental Española, 2001. Dossier de prensa.

18. Llodra JC, Bravo M Cortés FJ. Encuesta de salud oral de España (2000). RCOE 2002;7 (núm.especial):19-63.

19. Junta de Castilla y León. Estudio epidemiológico de la salud bucodental en los escolares de Castilla y León. Valladolid: Consejería de Sanidad y Bienestar Social. Junta de Castilla y León, 1995.

20. Junta de Castilla y León. Programa de Salud Bucodental en Castilla y León 1994-1997. Valladolid: Consejería de Sanidad y Bienestar Social. Junta de Castilla y León, 1998.

21. Junta de Castilla y León. Segundo Estudio Epidemiológico de la Salud Bucodental en los escolares en Castilla-León. Valladolid: Consejería de Sanidad y Bienestar Social. Junta de Castilla y León, 2000.

22. Estado de la salud oral en los escolares de Galicia: año 2000. Santiago de Compostela: Consellería de Sanidade. Dirección Xeral de Saúde Pública, 2000.

23. Montiel Company JM, Eustaquio Raga MV, Sánchez Acedo M, Almerich Silla JM. Hábitos de higiene oral en la población de 12 y 15 años de la comunidad valenciana. Póster presentado en SESPO Barcelona 2002. (accedido el 15 de junio de 2005 en http://www.infomed.es/sespo/bcn2002/sespodef.pdf) 